\title{
Elevated Temperature Effects on the Plastic Anisotropy of an Extruded Mg-4 Wt Pct Li Alloy: Experiments and Polycrystal Modeling
}

\author{
MARCEL RISSE, MARTIN LENTZ, CHRISTOPH FAHRENSON, \\ WALTER REIMERS, MARKO KNEZEVIC, and IRENE J. BEYERLEIN
}

In this work, we study the deformation behavior of $\mathrm{Mg}-4$ wt pet $\mathrm{Li}$ in uniaxial tension as a function of temperature and loading direction. Standard tensile tests were performed at temperatures in the range of $293 \mathrm{~K}\left(20^{\circ} \mathrm{C}\right) \leq T \leq 473 \mathrm{~K}\left(200{ }^{\circ} \mathrm{C}\right)$ and in two in-plane directions: the extrusion and the transverse. We find that while the in-plane plastic anisotropy (PA) decreases with temperature, the anisotropy in failure strain and texture development increases. To uncover the temperature dependence in the critical stresses for slip and in the amounts of slip and twinning systems mediating deformation, we employ the elastic-plastic self-consistent polycrystal plasticity model with a thermally activated dislocation density based hardening law for activating slip with individual crystals. We demonstrate that the model, with a single set of intrinsic material parameters, achieves good agreement with the stress-strain curves, deformation textures, and intragranular misorientation axis analysis for all test directions and temperatures. With the model, we show that at all temperatures the in-plane tensile behavior is driven primarily by $\langle a\rangle$ slip and both $\langle c+a\rangle$ slip and twinning play a minor role. The analysis explains that the in-plane PA decreases and failure strains increase with temperature as a result of a significant reduction in the activation stress for pyramidal $\langle c+a\rangle$ slip, which effectively promotes strain accommodation from multiple types of $\langle a\rangle$ and $\langle c+a\rangle$ slip. The results also show that because of the strong initial texture, in-plane texture development is anisotropic since prismatic slip dominates the deformation in one test, although it is not the easiest slip mode, and basal slip in the other. These findings reveal the relationship between the temperature-sensitive thresholds needed to activate crystallographic slip and the development of texture and macroscopic PA.

DOI: $10.1007 / \mathrm{s} 11661-016-3780-4$

(C) The Minerals, Metals \& Materials Society and ASM International 2016

\section{INTRODUCTION}

Magnesium $(\mathrm{Mg})$ alloys are being increasingly researched and evaluated for several structural applications within the automotive, aerospace, and consumer electronic industries due to their high strength-to-weight ratio. The automobile industry, for instance, is already using cast $\mathrm{Mg}$ alloys. ${ }^{[1,2]}$ However, there are many other alloys, such as wrought $\mathrm{Mg}$ alloys, that possess much

MARCEL RISSE, Scientific Assistant, and WALTER REIMERS, Professor, are with the Metallische Werkstoffe, Technische Universität Berlin, Ernst-Reuter-Platz 1, 10587, Berlin, Germany. Contact e-mail: marcel.risse@tu-berlin.de MARTIN LENTZ, Postdoctoral Researcher, formerly with the Metallische Werkstoffe, Technische Universität Berlin, is now with the Hydro Aluminium Rolled Products $\mathrm{GmbH}$, Research and Development Bonn, P.O. Box 2468, 53014, Bonn, Germany. CHRISTOPH FAHRENSON, Technical Staff Member, is with the Zentraleinrichtung Elektronenmikroskopie, Technische Universität Berlin, Straße des 17. Juni 135, 10623, Berlin, Germany. MARKO KNEZEVIC, Assistant Professor, is with the Department of Mechanical Engineering, University of New Hampshire, Durham, NH, 03824. IRENE J. BEYERLEIN, Professor, is with the Department of Mechanical Engineering, Materials Department, University of California at Santa Barbara, Santa Barbara, CA, 93106.

Manuscript submitted June 6, 2016.

Article published online November 3, 2016 higher strengths. To use wrought $\mathrm{Mg}$ alloys, the main hurdle to overcome is their limited room-temperature ductility.

Enhancing the ductility of $\mathrm{Mg}$ alloys requires a better understanding of the plastic deformation mechanisms involved in their mechanical behavior. In $\mathrm{Mg}$ and its alloys, most often, $\langle a\rangle$ basal slip is the easiest slip mode to activate, and the other available modes, such as $\langle a\rangle$ prismatic slip or $\langle c+a\rangle$ pyramidal slip, are relatively harder ${ }^{[3-7]}$ For a polycrystalline $\mathrm{Mg}$ material to accommodate a general applied deformation, activation of different sets of slip systems within the differently oriented crystals in the polycrystal is needed. ${ }^{[7-12]}$ Accordingly, in the event that nonbasal slip is much more difficult to activate than basal slip, pronounced macroscopic plastic anisotropy (PA) and potential strain localizations and macroscale instabilities can occur, thereby lowering overall ductility and formability. ${ }^{[13-15]}$

As one solution, $\mathrm{Mg}$-Li alloys are being considered as attractive structural material candidates, not only for their intrinsic lightweightness, but also for long elongations in tension and compression tests and ease in room-temperature rolling compared to pure $\mathrm{Mg} .{ }^{[13,16]} \mathrm{It}$ was further shown in Reference 17 that the Mg-4 wt pct Li alloy exhibits less room-temperature PA compared to 
pure $\mathrm{Mg}$. These more desirable deformation responses have been attributed to higher contributions of prismatic and pyramidal slip. Some evidence has been provided in Reference 18, where transmission electron microscopy (TEM) analysis revealed that deformed $\mathrm{Mg}-15$ at. pet $\mathrm{Li}$ (conform to $\mathrm{Mg}-4.9$ wt pet $\mathrm{Li}$ ) contained a higher density and more uniform distributed $\langle c+a\rangle$ dislocations than pure $\mathrm{Mg}$.

Modeling efforts ranging from the polycrystal to atomic level have provided some insight into the relative amounts of activated slip during deformation. In References 16 through 18, polycrystal plasticity modeling was combined with mechanical testing to investigate the deformation mechanisms in Mg-4 wt pet Li. Despite using different modeling approaches, initial textures, and applied deformation states (compression, plane strain compression), the model results consistently showed that the activation stress for the basal $\langle a\rangle$ slip mode is the lowest followed by prismatic $\langle a\rangle$ and pyramidal $\langle c+a\rangle$ slip mode. They also suggested that the activity of pyramidal $\langle c+a\rangle$ slip was higher in $\mathrm{Mg}-4$ wt pct $\mathrm{Li}$ than conventional $\mathrm{Mg}$ alloys. ${ }^{[17]}$ Agnew et al. ${ }^{[13,18]}$ suggested that $\mathrm{Li}$ lowered the nonbasal stacking fault energy and increased the stability of nonbasal dislocation glide.

In $\mathrm{Mg}$ alloys, deformation twinning can be another important deformation mechanism in addition to slip, particularly if $c$-axis deformation is required. The two twin modes often reported in $\mathrm{Mg}$ and its alloys are the $\{10 \overline{1} 2\}\langle 10 \overline{1} \overline{1}\rangle$ extension twin and $\{10 \overline{1} 1\}\langle 10 \overline{1} \overline{2}\rangle$ contraction twin. ${ }^{[3]}$ While their twin shears are similar, being 0.1289 and 0.1377 , respectively, the twin-matrix orientation relationships are different, being 86.3 and $56.2 \mathrm{deg}$, respectively, about the $\langle 11 \overline{2} 0\rangle$ directions. The onset of twinning, particularly the latter twin, is usually thought to limit formability, and efforts have predominantly focused on suppressing twinning. ${ }^{[19]}$ However, for this alloy, room-temperature deformation can lead to profuse contraction twinning and double twinning (a contraction twin with internal extension twinning), ${ }^{[20]}$ without a noticeable change in the elongation to fracture. ${ }^{[15,21]}$ This robustness in spite of copious testing was attributed to the relative ease of activation of nonbasal slip systems.

To increase formability, $\mathrm{Mg}$ alloys are typically processed at elevated temperatures. However, most studies on $\mathrm{Mg}-4$ wt pet $\mathrm{Li}$ are carried out at room temperature. Similar detailed understanding of the change in slip and twinning mechanisms with temperature has not been established to our knowledge. As an exception, Al-Samman studied the deformation textures of $\mathrm{Mg}-4 \mathrm{wt}$ pct $\mathrm{Li}$ in-plane strain compression deformation at elevated temperatures. He concludes that prismatic slip contributed more to deformation than pyramidal $\langle c+a\rangle$ slip and twinning was less favorable as slip became easier to activate at elevated temperature $\left[T=673 \mathrm{~K}\left(400{ }^{\circ} \mathrm{C}\right)\right] \cdot{ }^{[16]}$

In this work, we study the deformation behavior of $\mathrm{Mg}-4$ wt pet $\mathrm{Li}$ in uniaxial tension as a function of temperature and loading direction. Predicting concurrently the temperature-dependent deformation response and microstructural evolution relies on accurate description of the dislocation kinetics of slip, intrinsic to the $\mathrm{Mg}-4$ wt pet Li crystal. Prior studies on temperature effects for this type of alloy used phenomenological hardening laws or did not treat the anisotropic elastic part of the response. Here we employ an elastic-plastic polycrystal model, called elastic-plastic self-consistent (EPSC), with a thermally activated dislocation density-based hardening law. As we will demonstrate, the constitutive model with one material parameter set achieves good agreement with the stress-strain curves, deformation textures, and intragranular misorientation axis analysis (IGMA) for the two in-plane loading directions and all four temperatures tested. From the measurements, we report that while the in-plane PA decreases with temperature, the anisotropy in failure strain and texture development increase. In all in-plane tension tests at all temperatures, the deformation behavior is driven primarily by $\langle a\rangle$ slip, with $\langle c+a\rangle$ slip and twinning playing a minor role. Nonetheless, we find that significant reductions in the activation stress for pyramidal $\langle c+a\rangle$ slip with temperature likely caused the in-plane PA to concomitantly decrease.

\section{MATERIAL AND EXPERIMENTS}

\section{A. Material}

Extruded sheet of Mg-4 wt pet Li alloy with a thickness of $2.0 \mathrm{~mm}$ and a width of $90 \mathrm{~mm}$ was used for the present work. Cast billets with a diameter of $123 \mathrm{~mm}$ and a length of $150 \mathrm{~mm}$ for the extrusion process were produced by the Leibniz University of Hannover (Department for Material Science). The sheet was manufactured at the Extrusion Research and Development Center (Technische Universität Berlin) using a direct extrusion process with an extrusion ratio of $R=$ $61: 1$ and a processing temperature of $573 \mathrm{~K}\left(300{ }^{\circ} \mathrm{C}\right)$. The extruded sheet was not annealed afterward.

\section{B. Microstructure Characterization}

In order to determine the initial microstructure, we employed EBSD. For these investigations, samples were prepared by grinding, polishing, and chemically polishing in a solution of $12 \mathrm{~mL}$ hydrochloric acid (37 pct), 8 $\mathrm{mL}$ nitric acid (65 pct), and $100 \mathrm{~mL}$ ethanol. Each polishing step was followed by cleaning the sample via ultrasound in ethanol. For optical microscopy, the samples were etched in addition. The etching solution consists of 5-g citric acid in $95-\mathrm{mL}$ distilled water. The EBSD microstructure analysis was carried out at ZELMI (Zentraleinrichtung für Elektronenmikroskopie, Technische Universität Berlin) using a Hitachi S-2700 scanning electron microscope with an integrated HKL-EBSD System and Nordlys II Detector. The step size was $0.3 \mu \mathrm{m}$.

Texture can greatly contribute to the PA of Mg alloys. To determine the initial texture and deformation textures, we used X-ray diffraction (XRD). These measurements used monochromatic Co $K_{\alpha}$ radiation to measure the 
intensity distribution of the $\{0002\},\{10 \overline{1} 0\},\{10 \overline{1} 1\}$, $\{10 \overline{1} 2\}$, and $\{11 \overline{2} 0\}$ reflections by tilting psi and rotating phi in 5 deg steps. The measuring spot was located in the halfway thickness of the samples. Using the software MATLAB with the integrated MTEX 3.3 package, ${ }^{[2]}$ we calculated the ODFs and recalculated the $\{0002\}$, $\{10 \overline{1} 0\}$, and $\{10 \overline{2} 0\}$ pole figures. The MTEX package was also used to generate the discrete texture input files required for the EPSC simulations. We found that 5000 grains are suitable to perform our crystal plasticity simulations.

Figures 1(a) and (b) show the as-extruded microstructure (longitudinal section) and texture of the Mg-4 wt pct $\mathrm{Li}$ sheet. The material exhibits a nearly fully recrystallized microstructure with few isolated elongated large grains in the extrusion direction (ED). The average grain size was determined to be $38 \mu \mathrm{m}( \pm 3 \mu \mathrm{m})$. Randomly distributed impurities consisting of $\mathrm{MgO}$, $\mathrm{Mg}(\mathrm{AL})_{x}(\mathrm{Si})_{y}$, and $\mathrm{Cu}$ were detected via energy-dispersive X-ray analysis. Based on the size and low volume fraction of these impurities, it is assumed that they can potentially influence the failure behavior but not significantly the activation of deformation mechanisms.

The texture, shown in Figure 1(b), was measured in the plane of the sheet parallel to the normal direction (ND). An outstanding observation is a split basal peak in the $\langle 0002\rangle$ basal pole figure, where the two maxima ( $\sim 6 \mathrm{mrd}$ ) are tilted $35 \mathrm{deg}$ from the ND toward the transverse direction (TD). Compared to the investigations from Gall et al., Li et al., and Huang et al., this basal pole split toward the TD is uncommon for $\mathrm{Mg}$ sheets where strong basal textures or a split toward the ED would have been expected instead. ${ }^{[23-25]}$

\section{Mechanical Testing}

The strong starting initial texture seen in Figure 1(b) will likely result in a plastically anisotropic deformation response, regardless of the test temperature. Therefore, tensile tests at all temperatures were carried out in two different directions. Figure 2 shows the orientations of the machined tensile specimens relative to the extruded $\mathrm{Mg}-4$ wt pct Li sheet geometry. The tensile specimens were removed at $0 \mathrm{deg}(\mathrm{ED})$ and at $90 \mathrm{deg}$ (perpendicular to the ED or TD). The specimens have a gage length of $27 \mathrm{~mm}$ and a width of $10 \mathrm{~mm}$. Their width-to-thickness ratio was fit to a value of at least 2.5 to satisfy DIN 50125 standard test requirements.

For tensile testing, we use a thermomechanical deformation test machine (Gleeble Systems 3800). These tests were performed at different temperatures: $293 \mathrm{~K}$, $373 \mathrm{~K}, 423 \mathrm{~K}$, and $473 \mathrm{~K}\left(20^{\circ} \mathrm{C}, 100{ }^{\circ} \mathrm{C}, 150{ }^{\circ} \mathrm{C}\right.$, and $\left.200{ }^{\circ} \mathrm{C}\right)$. Those above $473 \mathrm{~K}\left(200{ }^{\circ} \mathrm{C}\right)$ led to elongations to failure that were out of the measurement range of the mechanical testing machine; hence, these will not be discussed further. The specimen was resistance heated with a heating rate of $5 \mathrm{~K} \mathrm{~s}^{-1}$. The temperature was controlled in situ by three thermocouples that were welded onto the surface at equidistant intervals along the gage length. Afterward, the tensile test was performed in strain-rate control at a quasi-static value of $2.6 \times 10^{-4} \mathrm{~s}^{-1}$.

\section{MULTISCALE POLYCRYSTAL MODELING}

\section{A. Summary of the EPSC Polycrystal Model}

To reveal the deformation mechanisms, including their activation stresses and hardening behavior, we will employ the EPSC model. ${ }^{[26]}$ EPSC is a polycrystal plasticity model that relates the response of an aggregate to that of each of its single crystals. In the model, each crystal has a specific orientation, ellipsoidal shape, and volume fraction. To calculate the stress and strain response of each crystal within the polycrystal, it is treated as an elastoplastic inclusion embedded within a homogeneous equivalent medium (HEM). A self-consistent scheme is used to calculate the properties of the HEM, the polycrystal, by enforcing that it equals the average properties of all its constituent crystals.

In what follows, we briefly review the EPSC model. Regarding notation, we use "." to denote a contracted or dot product and " $\otimes$ " for an uncontracted or tensor dyadic product.

The relationship between the macroscopic stress and strain increments is given by the following linear relationship:

$$
\mathrm{d} \boldsymbol{\sigma}=L \mathrm{~d} \boldsymbol{\varepsilon}
$$
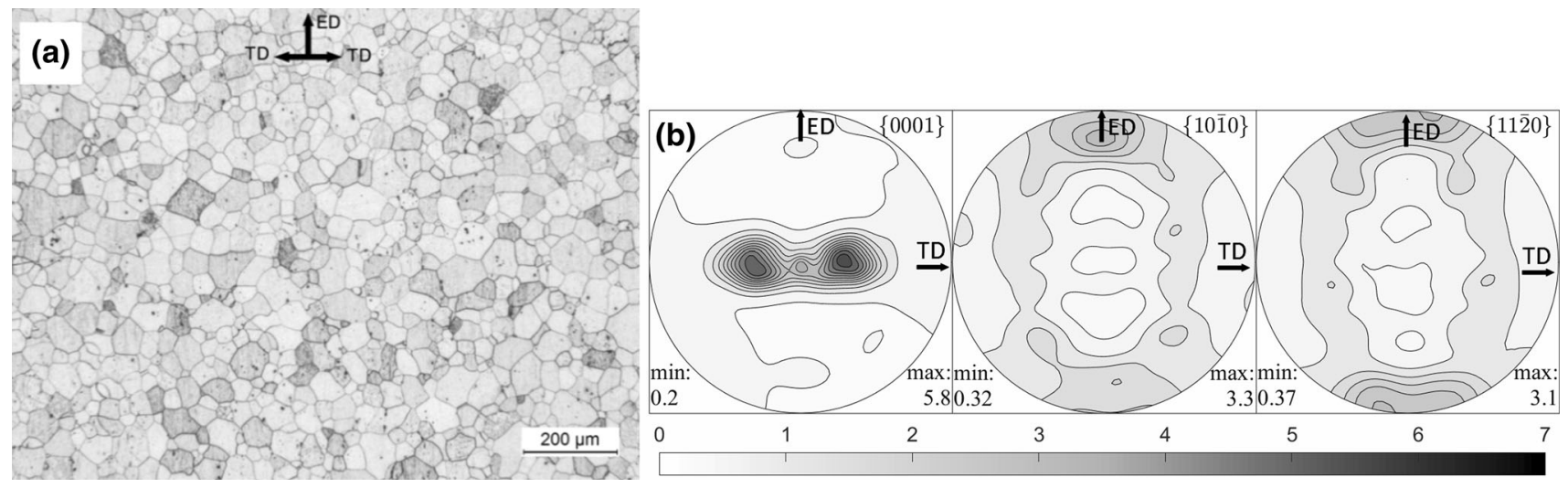

Fig. 1-(a) Initial microstructure of the L4-sheet and (b) initial texture of the L4-sheet. 


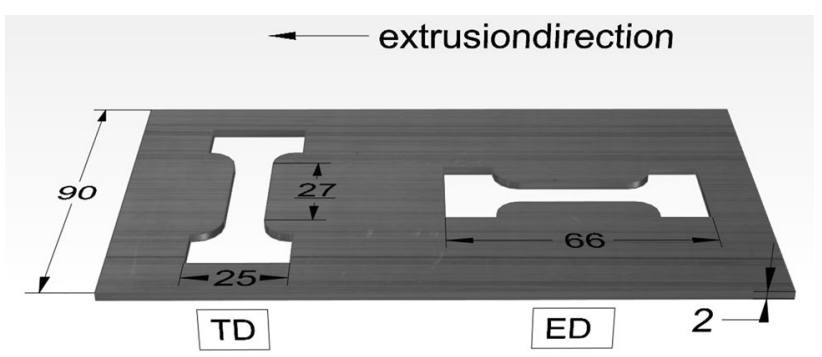

Fig. 2-Schematic drawing of the sample orientations in the L4-sheet.

where $\mathbf{L}$ is the instantaneous elastoplastic stiffness tensor of the polycrystal. It is unknown and solved for iteratively through a self-consistent procedure. ${ }^{[26]}$ This procedure satisfies stress equilibrium and strain compatibility. To solve for it, we begin with the relationship between the local strain increment for the individual crystals $\mathrm{c}$ and the macroscopic strain increment:

$$
\mathrm{d} \varepsilon^{c}=A^{c} \mathrm{~d} \boldsymbol{\varepsilon}
$$

where $A^{c}=\left(L^{c}+L^{c^{*}}\right)^{-1}\left(L^{c^{*}}+L\right)$ is the localization tensor for the elastoplastic ellipsoidal inclusion, a "model" crystal. $\mathbf{A}^{c}$ depends on both the $\mathbf{L}^{c}$ is the instantaneous elastoplastic stiffness tensor for crystal $\mathrm{c}$ and $L^{c^{*}}$, the effective stiffness, which is obtained via

$$
L^{c^{*}}=L\left(S^{c^{-1}}-I\right)
$$

where $\mathbf{S}^{c}$ is the symmetric Eshelby tensor ${ }^{[27]}$ and $\mathbf{I}$ is the fourth rank identity matrix.

The effective stiffness $L^{c^{*}}$ relates the stress and total strain increment in crystal $\mathrm{c}$ with those of the polycrystal through the following interaction equation:

$$
\left(\mathrm{d} \boldsymbol{\sigma}^{c}-\mathrm{d} \boldsymbol{\sigma}\right)=L^{c^{*}}\left(\mathrm{~d} \boldsymbol{\varepsilon}^{c}-\mathrm{d} \boldsymbol{\varepsilon}\right)
$$

Enforcing the self-consistent condition, in which the macroscopic stress and strain increments are equal to the volume average of the grain stress and strain increments gives

$$
\mathrm{d} \boldsymbol{\sigma}=\left\langle\mathrm{d} \boldsymbol{\sigma}^{c}\right\rangle
$$

and

$$
\mathrm{d} \boldsymbol{\varepsilon}=\left\langle\mathrm{d} \boldsymbol{\varepsilon}^{c}\right\rangle
$$

Finally, considering Eqs. [1] through [4], the macroscopic stiffness $\mathbf{L}$ becomes

$$
L=\left\langle L^{c} A^{c}\right\rangle\left\langle A^{c}\right\rangle^{-1}
$$

With the above, $\mathbf{L}$ is calculated for the current deformation increment, $n$.

According to Eq. [1], with L, the corresponding macroscopic stress $\boldsymbol{\sigma}^{n}$ at increment $n$ can be calculated from that of the previous increment, $n-1$, e.g., $\boldsymbol{\sigma}^{n}=\boldsymbol{\sigma}^{n-1}+\mathrm{d} \boldsymbol{\sigma}$. To calculate $\mathrm{d} \boldsymbol{\sigma}$, the stress increments $\mathrm{d} \boldsymbol{\sigma}^{c}$ for all constituent crystals are needed (Eq. [3]). For a given grain $\mathrm{c}, \mathrm{d} \boldsymbol{\sigma}^{c}$ is related to its strain increment, $\mathrm{d} \boldsymbol{\varepsilon}^{c}$, via the following constitutive relationship:

$$
\mathrm{d} \boldsymbol{\sigma}^{c}=C^{c}\left(\mathrm{~d} \boldsymbol{\varepsilon}^{c}-\sum_{s} m^{s} \mathrm{~d} \gamma^{s}\right)
$$

where $C^{c}$ is the single-crystal elastic stiffness tensor and the $\operatorname{sum} \sum_{s} m^{s} \mathrm{~d} \gamma^{s}$ is the plastic strain increment. It depends on the sum of shear strain increments $d \gamma^{s}$, from each slip system s, and the symmetric portion of the Schmid tensor for slip system s, expressed as

$$
m^{s}=0.5\left(b^{s} \otimes n^{s}+n^{s} \otimes b^{s}\right)
$$

where $\mathbf{b}^{s}$ and $\mathbf{n}^{s} \otimes \mathbf{b}^{s}$ are the unit vectors for the slip direction and slip plane normal, respectively.

In calculating $\mathbf{C}^{c}$ in Eq. [6], we take into account texture evolution by updating $\mathbf{C}^{c}$ at the beginning of each deformation increment according to the current orientation of the grain c. For $\mathrm{Mg}-4$ wt pet $\mathrm{Li}$, the invariant elastic single-crystal constants are $C_{11}=$ $56.3 \mathrm{GPa}, C_{12}=24.6 \mathrm{GPa}, C_{13}=20.7 \mathrm{GPa}, C_{33}=58.2$ $\mathrm{GPa}$, and $C_{44}=15.2 \mathrm{GPa}{ }^{[28]}$

Two criteria are used to activate a slip system: (1) $m^{s} \cdot \boldsymbol{\sigma}^{c}=\tau_{c}^{s}$, when the resolved shear stress equals the physical resistance to slip $\tau_{c}^{s}$; and (2) $m^{s} \cdot \mathrm{d} \boldsymbol{\sigma}^{c}=\mathrm{d} \tau_{c}^{s}$, which indicates that the stress has to remain on the single-crystal yield surface. These criteria do not allow for negative shear to happen on a given slip system. Because we wish to permit shear in both senses, we divide each slip system into two slip systems having the same plane normal but opposite senses of shearing.

The relationship between the increments in slip resistance, $d \tau_{c}^{s}$, and the shear increments, $d \gamma^{s \prime}$, is

$$
\mathrm{d} \tau_{c}^{s}=\sum_{s \prime} h^{s s \prime} \mathrm{d} \gamma^{s \prime}
$$

where $h^{s s \prime}$ is the hardening matrix. Expressions for $h^{s s t}$ are given in References 29 and 30.

Finally, the stress increment and strain increment of grain $\mathrm{c}$ are linearly related according to

$$
\mathrm{d} \boldsymbol{\sigma}^{c}=L^{c} \mathrm{~d} \varepsilon^{c}
$$

where $\mathbf{L}^{c}$ is given by

$$
L^{c}=C^{c}\left(I-\sum_{s} m^{s} \otimes\left(\sum_{s^{\prime}}\left(X^{s s^{\prime}}\right)^{-1} m^{s^{\prime}} C^{c}\right)\right)
$$

with

$$
X^{s s^{\prime}}=h^{s s^{\prime}}+C^{c} \cdot m^{s} \otimes m^{s^{\prime}}
$$

\section{B. Hardening Law}

During deformation, dislocations interact and become stored inside the crystal, acting as obstacles to dislocation motion and increasing their critical resolved shear stress (CRSS) with strain. The evolution of stored dislocations depends on temperature as well as the applied strain rate. Rate laws for the storage of a particular dislocation (basal, prismatic, pyramidal) with 
strain depend on many parameters characteristic of those dislocations and the material. The EPSC model uses a dislocation density-based hardening model to determine the evolution of the CRSS of each slip system, in each crystal, with strain and temperature. The hardening law is reviewed below and the reader is referred to Reference 31 for more details.

The resistance to slip $\tau_{c}^{s}$ is given by a sum of many contributions:

$$
\tau_{c}^{s}=\tau_{o}^{s}+\tau_{0, \mathrm{HP}}^{s}+\tau_{\mathrm{for}}^{s}+\tau_{\mathrm{sub}}^{s}
$$

where $\tau_{o}^{s}$ is a friction stress dependent on the Peierls stress and the initial content of dislocations, $\tau_{0, \mathrm{HP}}^{s}$ is a barrier term dependent on initial grain size, and $\tau_{\text {for }}^{s}$ and $\tau_{\text {sub }}^{s}$ are the forest and debris interaction stresses that evolve with strain.

The grain-size-dependent barrier effect term $\tau_{0, \mathrm{HP}}^{s}$ is included as a Hall-Petch effect via

$$
\tau_{0, \mathrm{HP}}^{s}=\mu^{s} H^{s} \sqrt{\frac{b^{s}}{d_{g}}}
$$

where $\mu^{s}$ is the effective shear modulus for each slip system, $\mathrm{s} ; H^{s}$ is the dimensionless constant, which when multiplied by the square root of the magnitude of the Burgers vector, $\mathbf{b}^{s}$, and $\mu^{s}$ gives the Hall-Petch coefficient; and $d_{g}$ is the grain size. The Burgers vectors are $3.21 \times 10^{-10} \mathrm{~m}$, $3.21 \times 10^{-10} \mathrm{~m}$, and $6.12 \times 10^{-10} \mathrm{~m}$ for the basal, prismatic, and pyramidal slip modes, respectively. The shear modulus is calculated from the updated $\mathbf{C}^{c}$.

In most cases, twin boundaries serve as barriers to slip. When twins are present, to model this barrier effect, $\tau_{0, \mathrm{HP}}^{s}$ is updated to include the mean free path $d_{\mathrm{mfp}}$ between adjacent twin boundaries; i.e.,

$$
\tau_{0, \mathrm{HP}}^{s}=\mu^{s} H^{s} \sqrt{\frac{b^{s}}{d_{\mathrm{mfp}}}}
$$

The $d_{\mathrm{mfp}}$ value is defined along the slip plane of the slip system s between two adjacent boundaries of the predominant twin system. If no twins are present, then the mean free path is $d_{\mathrm{mfp}}=d_{g}$. As the twins form and thicken, the matrix region shrinks and the mean free path $d_{\mathrm{mfp}}=d_{t}$ reduces. ${ }^{[32]}$

The evolution of $\tau_{\text {for }}^{s}$ is dependent on the evolution of the spatially random distribution of stored dislocations and is related to the stored forest dislocation density $\rho_{\text {for }}^{s}$ by start initial scan here:

$$
\tau_{\text {for }}^{s}=\chi^{s} b^{s} \mu^{s} \sqrt{\rho_{\text {for }}^{s}},
$$

where $\chi^{s}$ is a dislocation interaction parameter of order unity. For this work, and as in prior works, we set this parameter to 0.9 for each slip system, s. It is not used as a fitting parameter.

The $\tau_{\text {sub }}^{S}$ is dependent on an ordered distribution of stored dislocations, and its relationship to the substructure density $\rho_{\text {sub }}^{s}$ is given by the following extended Taylor-type law:

$$
\tau_{\mathrm{sub}}^{s}=k_{\mathrm{sub}} b^{s} \mu^{s} \sqrt{\rho_{\mathrm{sub}}} \log \left(\frac{1}{b^{s} \sqrt{\rho_{\mathrm{sub}}}}\right)
$$

where $k_{\text {sub }}=0.086$ is a mathematical constant. To represent a dynamically recrystallized material, the initial values of dislocation density are set to $1.5 \times 10^{12} \mathrm{~m}^{-2}$ for $\rho_{\text {for }}^{s}$ and $0.1 \mathrm{~m}^{-2}$ for $\rho_{\text {sub }}^{s}$.

The density $\rho_{\text {for }}^{s}$ evolves according to References 33 through 35:

$$
\frac{\partial \rho_{\text {for }}^{s}}{\partial \gamma^{s}}=\frac{\partial \rho_{\text {gen,for }}^{s}}{\partial \gamma^{s}}-\frac{\partial \rho_{\text {rem,for }}^{s}}{\partial \gamma^{s}}=k_{1}^{s} \sqrt{\rho_{\text {for }}^{s}}-k_{2}^{s}(\dot{\varepsilon}, T) \rho_{\text {for }}^{s},
$$

$$
\Delta \rho_{\text {for }}^{s}=\frac{\partial \rho_{\text {for }}^{s}}{\partial \gamma^{s}}\left|\Delta \gamma^{s}\right|
$$

where $k_{1}^{s}$ is a rate-insensitive coefficient, which accounts for dislocation storage due to statistical trapping of glide dislocations by forest obstacles; $\gamma^{s}$ is the shear strain; $\frac{\partial \rho_{\mathrm{gen}, \mathrm{for}}^{s}}{\partial \gamma^{s}}$ is the rate of dislocation generation (or storage); and $\frac{\partial \rho_{\text {rem,for }}^{s}}{\partial \gamma^{s}}$ is the rate of dislocation removal. The coefficient $k_{2}^{s}$ is a rate-sensitive coefficient for dynamic recovery by thermally activated mechanisms and is given by

$$
\frac{k_{2}^{s}}{k_{1}^{s}}=\frac{\chi^{s} b^{s}}{g^{s}}\left(1-\frac{\mathrm{k} T}{D^{s}\left(b^{s}\right)^{3}} \ln \left(\frac{\dot{\varepsilon}}{\dot{\varepsilon}_{0}}\right)\right)
$$

where $k, \dot{\varepsilon}$, and $\dot{\varepsilon}_{0}=1 \times 10^{7}$ are, respectively, the Boltzmann constant, the applied strain rate, and a reference strain rate; for slip system $s, g^{s}$ and $D^{s}$ are an effective activation enthalpy and a drag stress. by

Every twin system has an activation stress, $\tau_{c}^{t}$, given

$$
\tau_{c}^{t}=\tau_{o}^{t}+\tau_{0, \mathrm{HP}}^{t}+\mu^{t} \sum_{t} C^{s t} b^{t} b^{s} \rho_{\text {for }}^{s}
$$

where $\tau_{o}^{t}$ is a temperature-independent friction term, $\tau_{0, \mathrm{HP}}^{t}$ is a Hall-Petch-like barrier term, and the last term is a latent hardening term that hardens the twin system via the activity of slip. The friction term is calculated as $\tau_{o}^{t}=\tau_{\text {prop }}^{t}+\left(\tau_{\text {crit }}^{t}-\tau_{\text {prop }}^{t}\right) \exp \left(-\frac{\sum \rho_{\text {for }}^{s}}{\rho_{\text {sat }}^{s}}\right)$, where $\tau_{\text {crit }}^{t}$ and $\tau_{\text {prop }}^{t}$ are the nucleation and propagation stresses, whose contribution to twin activation is leveraged by the probability term $\frac{\sum \rho_{\mathrm{for}}^{s}}{\rho_{\mathrm{sat}}^{s}}$. The Burgers vector for the extension twin is $1.38 \times 10^{-10} \mathrm{~m}$. The Hall-Petch-like term for twinning is similar to that for slip. The term is affected by $d_{g}$ via

$$
\tau_{0, \mathrm{HP}}^{t}=\mu^{t} H^{t} \sqrt{\frac{b^{t}}{d_{g}}}
$$

And, when twins are present, $d_{g}$ changes to $d_{\mathrm{mfp}}$ : 


$$
\tau_{0, \mathrm{HP}}^{t}=\mu^{t} H^{t} \sqrt{\frac{b^{t}}{d_{\mathrm{mfp}}}}
$$

Twin reorientation within a grain is modeled using the twin inclusion model in Reference 30. In this model, the initial stress and strain state within the twins must be assigned. Here we use the finite initial fraction assumption $^{[36]}$ to provide these values.

\section{RESULTS}

\section{A. Mechanical Properties}

Figure 3 presents the measured tensile stress-strain curves in the ED and TD at four different test temperatures from room temperature to $473 \mathrm{~K}$ (200 ${ }^{\circ} \mathrm{C}$ ). In Figure 3, we also plot the simulated tensile stress-strain curves, which we will discuss shortly. As shown, the experimental flow stresses from the ED and TD tests for a given temperature evolve with strain in a similar manner. The ED and TD responses also exhibit similar dependencies on temperature.

Deformation twinning is known to produce a signature change in hardening with strain in Mg alloys. Here (Figure 3) we observe no pronounced changes in hardening in both TD and ED, suggesting a low activity of both common twin modes. However, their absence does not necessarily mean that twinning did not occur.

Comparing the ED and TD tests, there are some important differences in the yield stress, initial hardening rate, and elongation to failure among these responses. Comparing data in Figures 3(a) and (b) shows that the yield stresses in the ED tests are more sensitive to temperature than those in the TD ( $c f$. Figure 4). We also observe a reduction in PA with temperature. To quantify this, in Figure 4, we plot the variation in the percentage difference in PA given by

$$
\mathrm{PA}=\left(\sigma_{Y}^{\mathrm{ED}}-\sigma_{Y}^{\mathrm{TD}}\right) / \sigma_{Y}^{\mathrm{ED}}
$$

where $\sigma_{Y}^{\mathrm{ED}}$ and $\sigma_{Y}^{\mathrm{TD}}$ are the yield stresses in the ED and TD directions, respectively. At $473 \mathrm{~K}\left(200{ }^{\circ} \mathrm{C}\right)$, the material behavior exhibits substantially reduced anisotropy in yield stress. We also notice that the strain hardening after yield is higher for the ED test compared to that for the TD tests. Last, in Figure 4, we plot the elongation to failure in the ED and TD as a function of temperature. As shown, the elastic strains to failure in both test directions increase with temperature. The tensile tests in the TD loaded specimen, however, exhibit higher elongations to fracture compared to those in the ED.

The observed differences in the ED and TD deformation responses could be due to differences in (1) the relative amounts of the $\langle a\rangle$ and $\langle c+a\rangle$ slip modes active during deformation and (2) texture evolution with strain. These factors are coupled, and it is difficult to determine the active deformation mechanisms from analyzing stress-strain behavior alone. In order to understand the underlying mechanisms, we study the deformation textures and the intragranular misorientations after deformation, and carry out EPSC simulations for all tests reported here.

\section{B. Texture Evolution}

From the flow curves alone, it is difficult to discern whether slip and twinning activities are similar between the test temperatures and loading directions. In this regard, more insight can be gained by analyzing deformation textures, since for hexagonal-close-packed metals, in most cases, distinct types of slip can lead to distinct features of texture. Figures 5(a) and 6(a) present the $\{0002\},\{10 \overline{1} 0\}$, and $\{11 \overline{2} 0\}$ pole figures for the initial and the ED and TD tensile-tested $\mathrm{Mg} 4$ wt pct $\mathrm{Li}$ sheet material for all test temperatures and at the failure strain. All pole figures are plotted in a stereographic projection, with the ND being normal to the figure. The deformed textures are measured in the center of the specimens after failure and away from the failed region.

As mentioned, the initial material was extruded, which produced a texture with two maxima in the basal pole figure located about $35 \mathrm{deg}$ from the ND. After tensile deformation, in all cases, the basal texture maintains the two maxima tilted toward the TD. Nonetheless, some noticeable and important changes in texture evolution have taken place as a result of tension testing in the ED and TD. In Figure 5(a), we observe that the ED deformation textures possess a split basal pole, and as in the initial texture, these two maxima remain at $35 \mathrm{deg}$ from the ND for all test temperatures from room temperature to $473 \mathrm{~K}\left(150^{\circ} \mathrm{C}\right)$. The $(10 \overline{1} 0)$ poles have aligned along the ED loading direction. They become more highly aligned for higher temperatures. Other temperature effects on texture development in the ED test are relatively minor. In Figure 6(a), we find that the TD deformation textures also possess a strong split basal peak texture, but the peaks are located closer to the ND than the starting texture. Unlike the ED deformation textures, the maxima location changes with temperature. As the temperature increases from $293 \mathrm{~K}, 373 \mathrm{~K}$, and $423 \mathrm{~K}$ to $473 \mathrm{~K}$ $\left(20{ }^{\circ} \mathrm{C}, 100{ }^{\circ} \mathrm{C}\right.$, and $150{ }^{\circ} \mathrm{C}$ to $\left.200{ }^{\circ} \mathrm{C}\right)$, the split decreases from 30,25 , and $20 \mathrm{deg}$ to $17.5 \mathrm{deg}$, respectively. Concurrently, as the temperature increases, the $(11 \overline{2} 0)$ poles become aligned along the ED (normal to the loading direction) and the (1010) pole figure develops a sixfold symmetry, so that the prismatic planes are oriented perpendicular to the sheet plane. These texture changes and differences between the ED and TD deformation textures indicate that the slip activities, that is, which slip systems are active and the relative amounts of shear on each, involved in ED and TD tension testing are not the same. This might be expected considering the impact of the load direction on the Schmid factors of the slip and twin modes. However, an accurate quantification of the contribution of the deformation modes requires crystal plasticity simulations, which will be discussed in Section IV-C. 


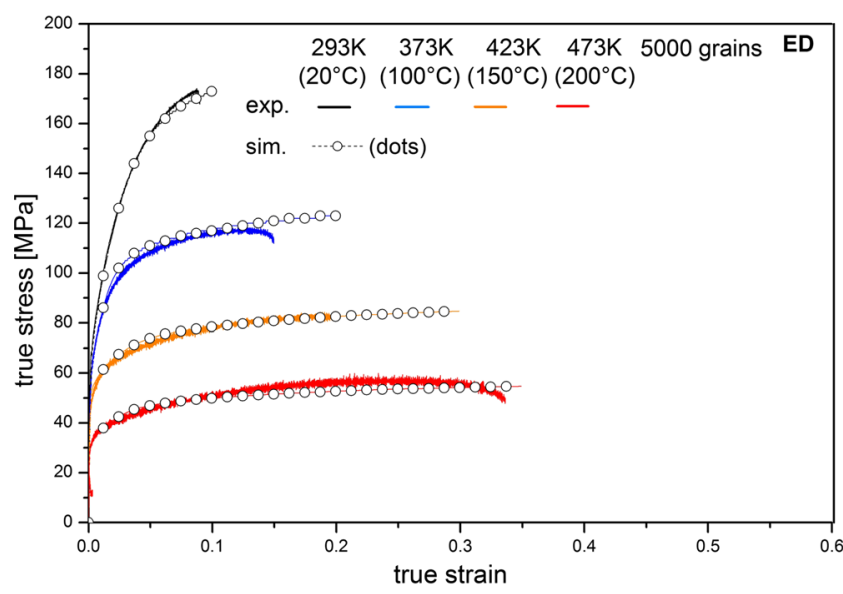

(a)

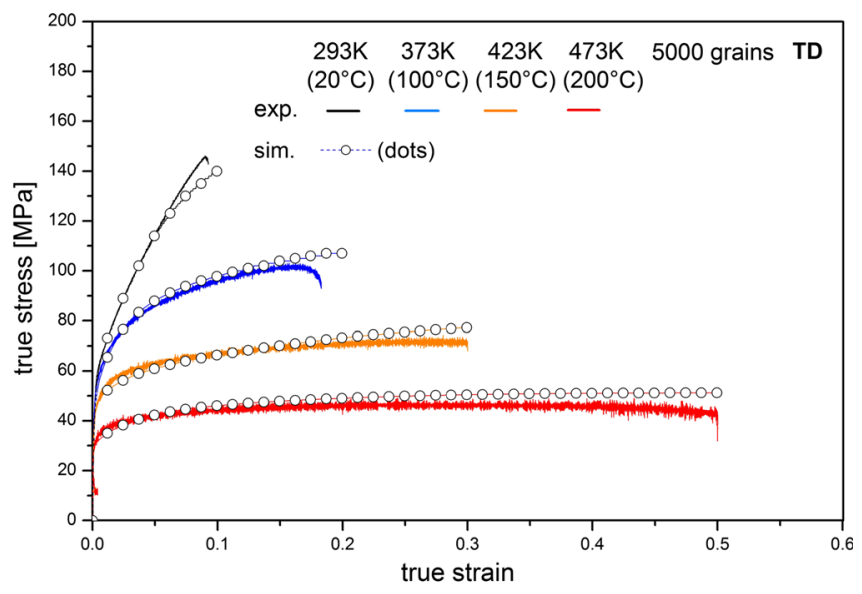

(b)

Fig. 3-Experimental and simulated tension flow curves in dependence of temperature and loading direction: $(a)$ ED and (b) TD (Color figure online).

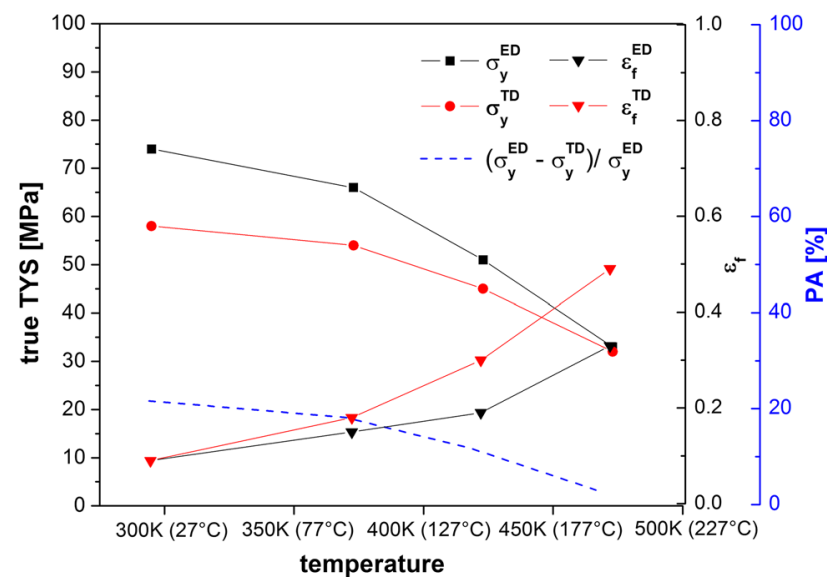

Fig. 4-Temperature dependence of TYS and $\varepsilon_{\mathrm{f}}$.

\section{Intragranular Misorientation Axis Analysis}

As one method for assessing slip activity at the polycrystal scale, we used IGMA. Intragranular misorientations are generated by slip-induced lattice rotations. The rotation axis, $\mathbf{R}$, can be associated with a type of slip and is given by ${ }^{[37-39]}$

$$
R=\gamma b \otimes n
$$

where $\mathbf{b}$ is the Burgers vector direction, $\mathbf{n}$ the slip plane normal, and $\gamma$ the shear strain of the slip system in question. Accordingly, we can use Eq. [25] to determine dominant slip modes by analyzing the rotation axis distribution in the deformed tensile specimens. The relationships between the three slip modes studied here and their corresponding rotation axis are given in Table I.

Figure 7 shows the IGMA distributions obtained from approximately 100 grains after ED and TD testing at room temperature and $473 \mathrm{~K}\left(200{ }^{\circ} \mathrm{C}\right)$. In the ED tension tests, the grains show lattice rotation axis distributions that are strongly concentrated around $\langle 0001\rangle$. Based on the relationship in Eq. [25] and
Table I, we see that this result indicates that deformation primarily involved prismatic $\langle a\rangle$ slip. It conforms to the EPSC simulation results in Figure 9, which will be discussed later. For the TD tests, IGMA distributions are not as strongly peaked at $\langle 0001\rangle$ and, particularly in the RT case, are virtually random. The following EPSC simulation results are reasonably consistent with these measurements in the sense that they show that while prismatic $\langle a\rangle$ slip became predominant near the end of straining, the deformation was accommodated by a mix of all slip modes.

\section{MODELING RESULTS}

To link deformation response, texture evolution, and operative slip and twinning, we employ the polycrystal EPSC model described in Section III. The EPSC model developed here is not constrained by the initial texture, test strain rates, test temperatures, and applied loading path(s). Moreover, it will provide insight into the relative activation barriers and hardening rates intrinsic to individual slip families.

The slip systems made available to the EPSC model are basal $\{0001\}\langle 11 \overline{2} 0\rangle$ slip, prismatic $\{1 \overline{1} 00\}\langle 11 \overline{2} 0\rangle$ slip, and second-order pyramidal $\langle c+a\rangle\{11 \overline{2} 2\}\langle 11 \overline{2} \overline{3}\rangle$ slip. We also included the $\{10 \overline{1} 2\}\langle 10 \overline{1} \overline{1}\rangle$ extension twinning systems. These slip modes together provide accommodation for a general deformation. Compression twinning as a deformation mode was not considered in the simulation due to a negligible volume fraction, which contributes to deformation. The negligible volume fraction of compression twins was observed by EBSD investigation. For $\mathrm{Mg}$ and $\mathrm{Mg}$ alloys, basal slip is the easiest $\langle a\rangle$ slip. $^{[5,6]}$ Prismatic $\langle a\rangle$ slip is relatively harder but thought to be more prominent in $\mathrm{Mg}-\mathrm{Li}$ alloys than in pure $\mathrm{Mg}^{[16,17]}$ For pyramidal $\langle c+a\rangle$ slip, there are two types of slip families, pyramidal type I and II slip, differing in the crystallographically of their glide plane. Over the years, 


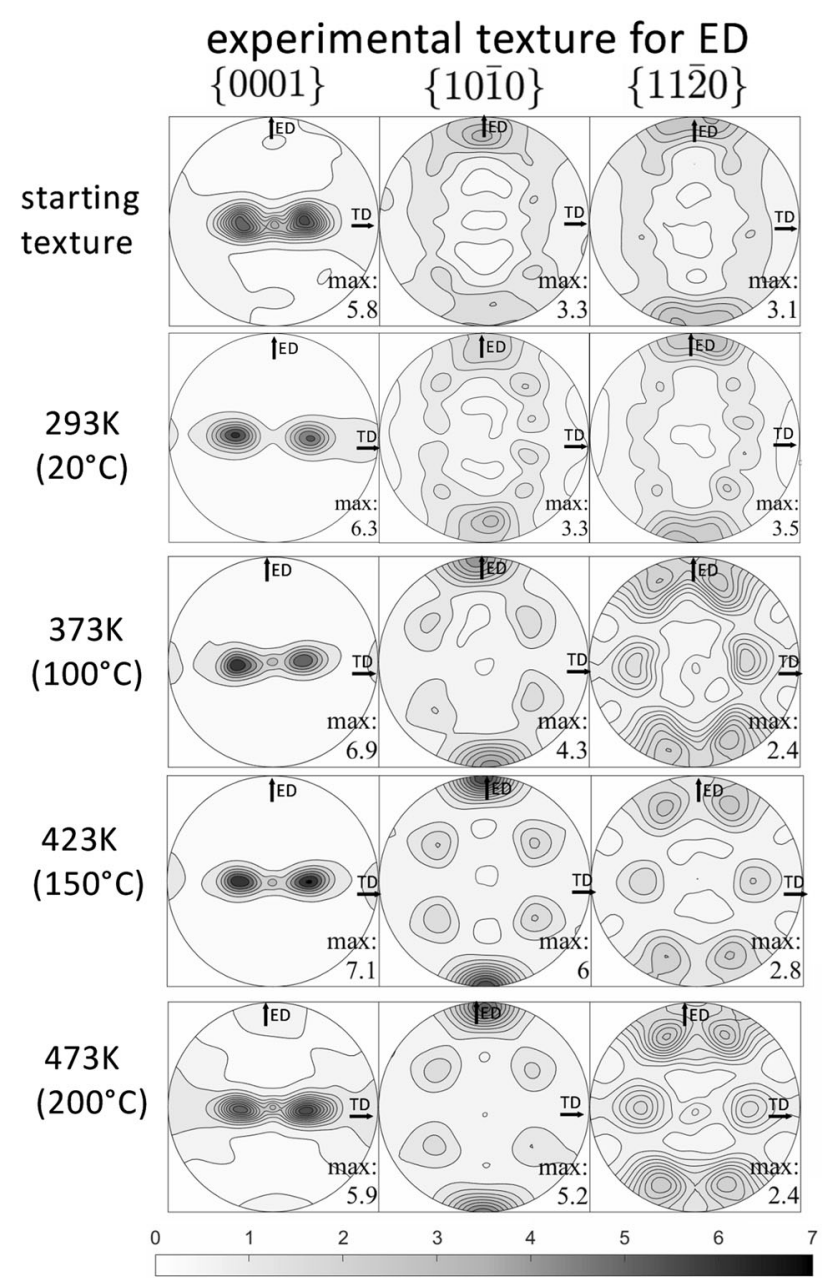

(a)
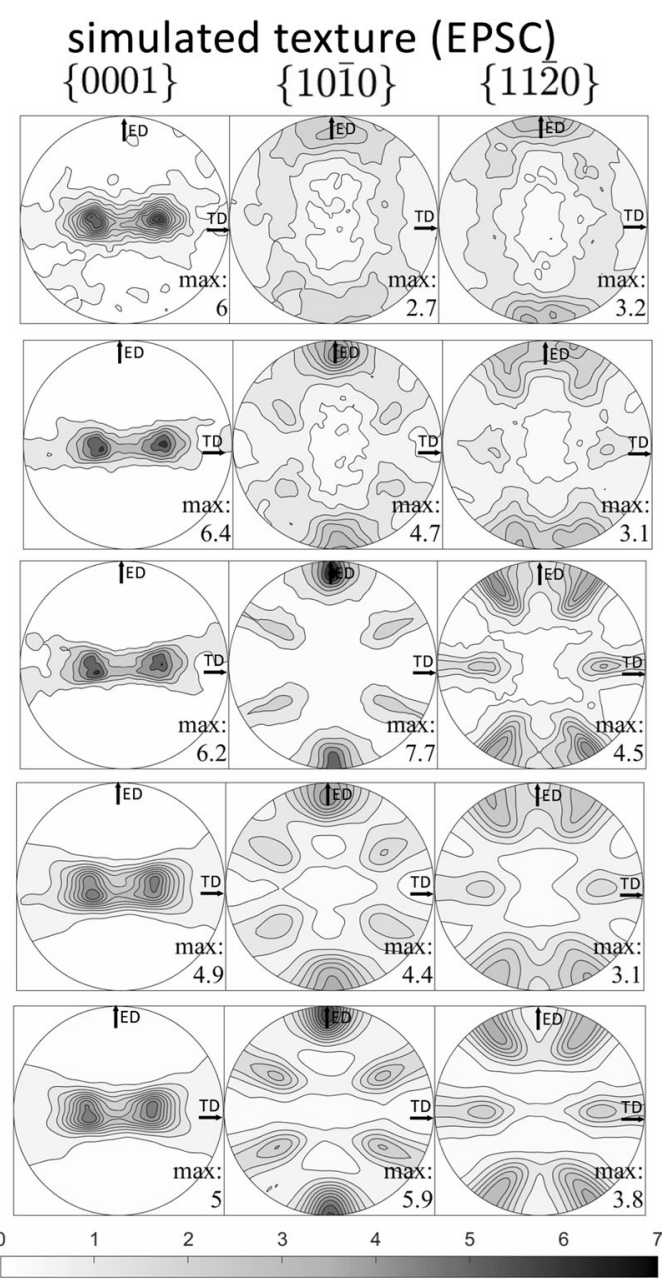

(b)

Fig. 5- (a) Experimental vs $(b)$ simulated texture development in dependence of the temperature for loading in the ED. The pole figures are plotted in stereographic projection.

studies via TEM, in-situ TEM, and slip trace analyses have provided evidence in support of both types. ${ }^{[11,40,41]}$ It remains to be seen whether texture calculations via crystal plasticity simulations can distinguish between the two. For the present simulations, we have elected to use pyramidal type II.

In the prior work of Lentz et al. ${ }^{[17]}$ the EPSC model was used to characterize the hardening parameters for these three slip systems and the twinning mode for $\mathrm{Mg}-4 \mathrm{wt}$ pct $\mathrm{Li}$ at room temperature only. In this work, having tests at multiple temperatures, we can better characterize material parameters associated with thermally activated recovery. A reliable parameter set can be obtained when a single set achieves favorable comparisons with all data (i.e., all stress-strain curves and texture evolution). To this end, we used half the experimental stress-strain curves, covering different temperatures and in both the ED and TD, such that all possible slip systems could be activated. The other half and all texture measurements were used for validation.

In the EPSC model simulations of tensile testing, we imported the ODFs representing the initial texture as recalculated from the XRD pole figures (Figure 1(b)). Five thousand distinct orientations were used to represent the texture. We assigned an initial spherical shape to all grains, assuming a negligible influence of the occasionally observed elongated grains. The grain shape and texture were allowed to evolve with strain in each test. As in the actual test, we set the applied model strain rate to $2.6 \times 10^{-4} \mathrm{~s}^{-1}$.

Figure 3 compares the simulated stress-strain curves for both loading directions in the ED and TD with the experimentally measured loading behavior. With a single set of parameters, the EPSC model is seen to capture well the yield stress, flow stress, and hardening rates in the stress-strain curves for the range of test temperatures and tensile directions. The final set of material parameters is given in Table II.

In Figures 5(b) and 6(b), we present the corresponding calculated textures from the EPSC simulations for the ED and TD tests. Generally, we find that the calculated textures achieve good agreement in all cases. The model captures the location of the basal pole maxima in the ED textures and the apparent stability of these maxima with respect to changes in temperature. Notably, it also predicts the split peaks in the TD textures and the changes in their location as temperature 


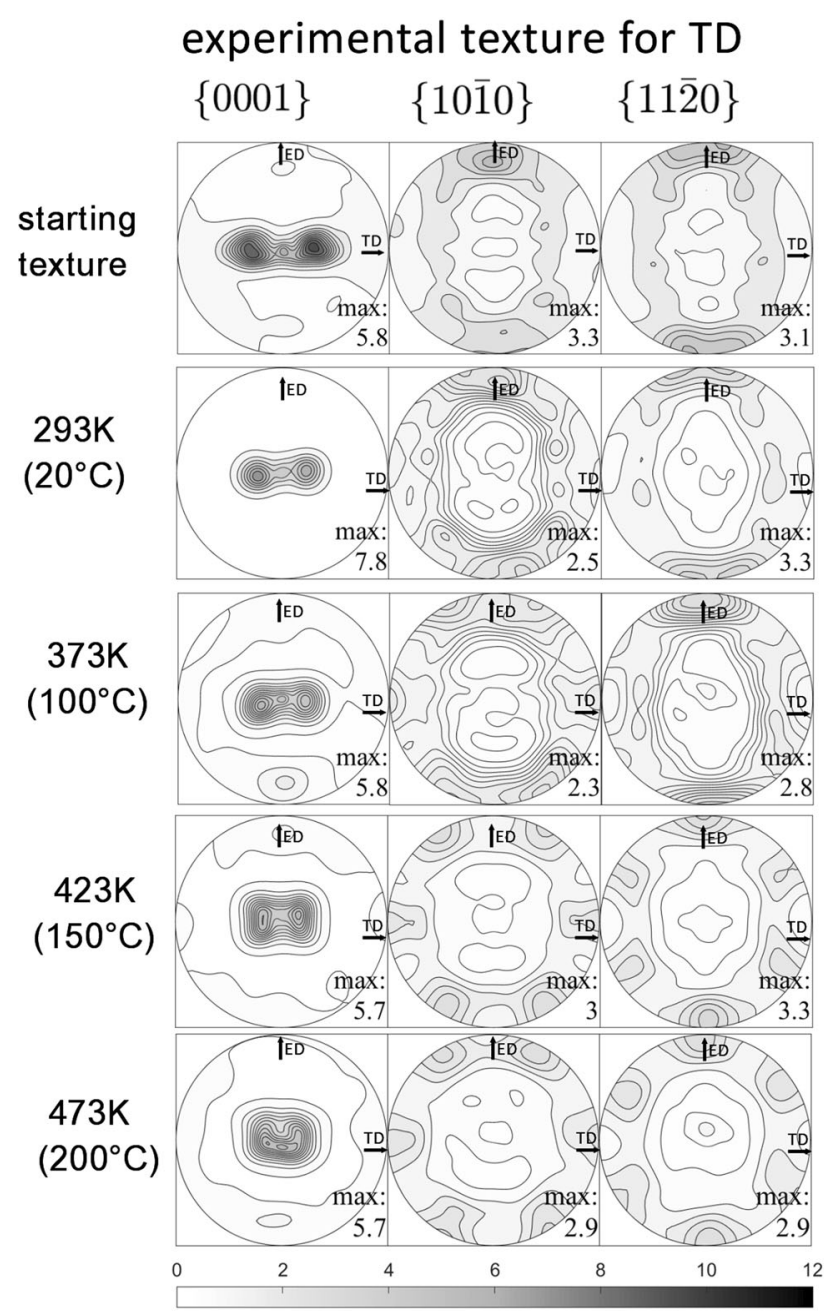

(a)

\section{simulated texture (EPSC)}
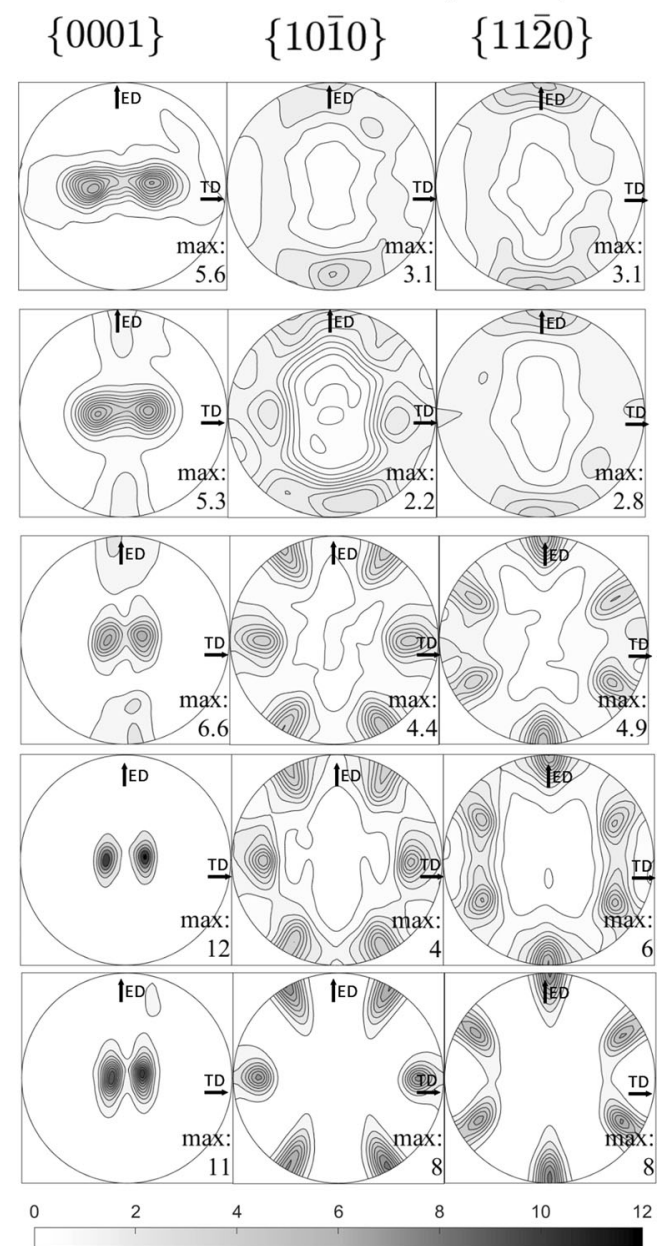

(b)

Fig. 6-(a) Experimental vs (b) simulated texture development in dependence of the temperature for loading in the TD. The pole figures are plotted in stereographic projection.

Table I. Slip Modes and the Corresponding Rotation Axis

\begin{tabular}{lcc}
\hline Slip Type & Slip Mode & Rotation Axis \\
\hline Basal $\langle a\rangle$ & $\{0001\}\langle 11 \overline{2} 0\rangle$ & $\langle 1 \overline{1} 00\rangle$ \\
Prismatic $\langle a\rangle$ & $\{1 \overline{1} 00\}\langle 11 \overline{2} 0\rangle$ & $\langle 0001\rangle$ \\
Pyramidal $\langle c+a\rangle$ & $\{1 \overline{2} 2\}\langle 11 \overline{2} \overline{3}\rangle$ & $\langle\overline{1} 100\rangle$ \\
\hline
\end{tabular}

increases. In addition, the calculated textures possess the development of the sixfold symmetry in the $\{10 \overline{1} 0\}$ pole figure.

The accurate predictions for stress-strain behavior and texture evolution of several tests can be considered an outcome of reasonable values for the hardening parameters for slip and twinning, both in their relative order and temperature sensitivities. Figure 8 shows the corresponding initial CRSS $\tau_{o}(\mathrm{MPa})$ values as a function of temperature. The temperature dependence of $\tau_{o}^{S}$ is given by

$$
\tau_{o}^{s}=A^{s} /\left(1+\exp \left(B^{s}\left(T-C^{s}\right)\right)\right)
$$

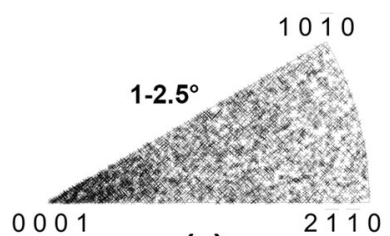

(a)

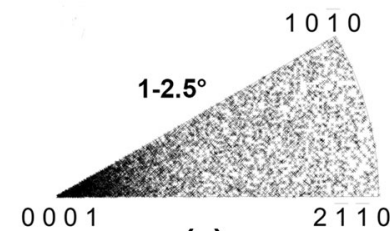

(c)

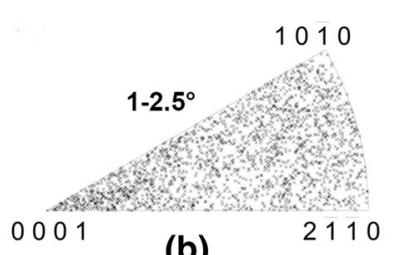

(b)

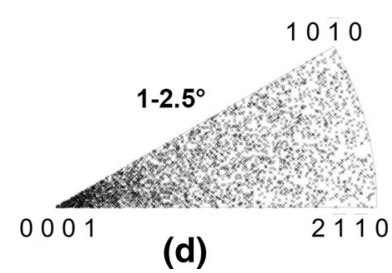

(d)
Fig. 7-IGMA analysis and texture of the EBSD data: (a) ED 293 $\mathrm{K}\left(20{ }^{\circ} \mathrm{C}\right),(b)$ TD $293 \mathrm{~K}\left(20^{\circ} \mathrm{C}\right),(c) \mathrm{ED} 473 \mathrm{~K}\left(200{ }^{\circ} \mathrm{C}\right)$, and $(d)$ TD $473 \mathrm{~K}\left(200{ }^{\circ} \mathrm{C}\right)$.

where $A, B$, and $C$ are material parameters. In Figure 8, we see that basal slip is the easiest, followed by prismatic slip, and pyramidal slip is the hardest. This ranking is 
Table II. Hardening Parameters for the Three Slip Modes and the Tensile Twinning Mode in L4

\begin{tabular}{|c|c|c|c|c|c|}
\hline Parameter & $\langle a\rangle$ Prism & $\langle a\rangle$ Basal & $\langle c+a\rangle \mathrm{Pyr}$ & Parameter & TTW \\
\hline$\tau_{\mathrm{o}}^{s}(\mathrm{MPa})$ & Eq. [26] & Eq. [26] & Eq. [26] & $\tau_{\text {crit }}^{t}(\mathrm{MPa})$ & 25 \\
\hline$A^{\mathrm{s}}$ & 19.6 & 0.97 & 99.53 & & \\
\hline$B^{\mathrm{s}}$ & 0.03 & 0.02 & 0.04 & & \\
\hline$C^{\mathrm{s}}$ & 424.8 & 382.83 & 379.86 & & \\
\hline$k_{1}^{s}\left(\mathrm{~m}^{-1}\right)$ & $8.0 \mathrm{E}+08$ & $0.8 \mathrm{E}+08$ & $7.5 \mathrm{E}+07$ & $\tau_{\text {Prop }}^{t}(\mathrm{MPa})$ & 75 \\
\hline$H^{s}$ & 0.05 & 0 & 0.025 & $H^{t}$ & 0.106 \\
\hline$D^{\mathrm{s}}(\mathrm{MPa})$ & Eq. [27] & $1.5 \mathrm{E}+03$ & $3.3 \mathrm{E}+03$ & - & - \\
\hline$g^{s}(-)$ & $3.3 \mathrm{E}-03$ & $2.0 \mathrm{E}-03$ & $2.0 \mathrm{E}-03$ & - & - \\
\hline$\rho_{0}\left(\mathrm{~m}^{-2}\right)$ & $1.5 \mathrm{E}+12$ & $1.5 \mathrm{E}+12$ & $1.5 \mathrm{E}+12$ & - & - \\
\hline$C^{s t}(-)$ & 50 & 50 & 450 & - & - \\
\hline
\end{tabular}

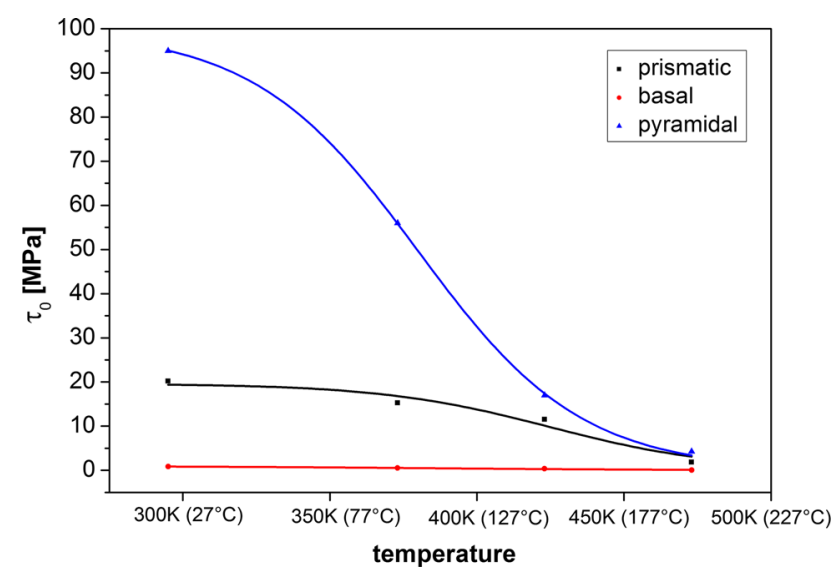

Fig. 8-Fitted $\tau_{\boldsymbol{o}}^{\boldsymbol{s}}$ as a function of temperature.

consistent with the results from the works of others on the same or similar Mg-Li alloys. ${ }^{[16-18]}$ We also find that temperature profoundly impacts the initial barrier for pyramidal slip but only mildly for basal and prismatic slip. The pronounced CRSS drop for pyramidal slip agrees with measurements made in single crystals of pure Mg. ${ }^{[11,42]}$ Consequently, as temperature increases, the CRSS values for the different slip modes as well as twinning draw closer and the crystal intrinsically becomes less anisotropic. Thus, the reduction in the ED-TD PA of the polycrystal with the increase in temperature seen in Figure 4 is a result of the significant drop in the CRSS of pyramidal slip.

The analysis also suggests that the kinetics involved in the dynamic recovery of prismatic slip is temperature sensitive, more so than that of pyramidal or basal slip. The variation in the drag stress $D^{s}$ for prismatic slip is given by

$$
D^{s}=E+F \exp \left(\frac{-T}{G}\right)
$$

where $E, F$, and $G$ are $3.25 \times 10^{3}, 2.27 \times 10^{9}$, and 27.05 , respectively. The result suggests a strong temperature-dependent mobility of prismatic dislocations. Experiments have shown that screw dislocations on prismatic planes in pure $\mathrm{Mg}$ experience a high friction stress and move through the lattice via a kink-pair mechanism. ${ }^{[43,44]}$ This motion becomes easier with temperature, becoming a thermal at $700 \mathrm{~K}\left(427{ }^{\circ} \mathrm{C}\right)$. The significant temperature sensitivity of $D$ for prismatic slip captured in this model is likely connected to the highly thermally activated glide. It may also be a reflection of the increased favorability of cross-slip of prismatic dislocations with temperature. ${ }^{[45]}$

\section{DISCUSSION}

The differences seen experimentally in yield, elongation to failure, and texture evolution in the ED and TD tests indicate that different proportions of basal, prismatic, pyramidal slip, and twinning were active during deformation. Further, good agreement in both texture and stress-strain responses achieved by the model shows that the underlying deformation mechanisms used in the model should be sufficiently reliable. To examine the contributions of slip and twinning in all tests, we extract from these calculations predictions of their participation at every strain level in deformation response.

As one measure of slip or twin activity, we elect to calculate the relative activity for each slip family and twin mode averaged over the polycrystal. From the simulation, at every time (or strain) increment, we obtain the relative activity $\left(\mathrm{RA}^{\alpha}\right)$ for a given slip or twin mode $\alpha$ in each grain using

$$
\mathrm{RA}^{\alpha}=\frac{\sum_{\alpha} \dot{\gamma}^{s}}{\sum_{s}^{N} \dot{\gamma}^{s}}
$$

where $\dot{\gamma}^{s}$ is the slip rate for a given slip system s, and the sum in the numerator is taken over all systems belonging to the $\alpha$ family. The sum in the denominator spans $N$, the number of slip and twinning systems, and corresponds to the strain contributed by all modes of slip and twinning in the grain. Finally, $\mathrm{RA}^{\alpha}$ for a particular mode $\alpha$ is then averaged over all grains in the polycrystal.

Figure 9 shows $\mathrm{RA}^{\alpha}$ for slip and twinning at all temperatures and loading directions. In all cases, all three slip modes and extension twinning contribute. Yet, for the most part, the amounts of each slip and twinning mode are not the same for the ED and TD tests. The initial texture is strong (Figure 1(a)); thus, tensile testing along the TD vs ED would be expected to activate 


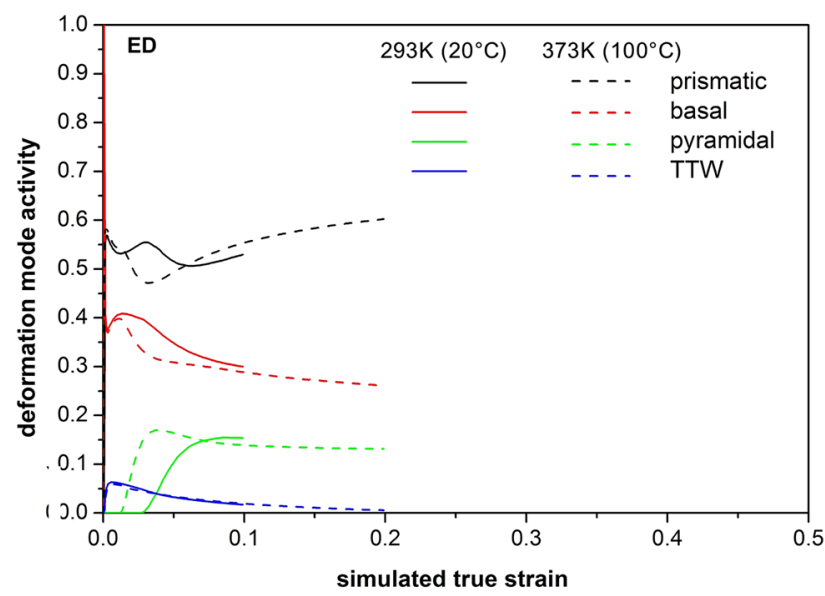

(a)

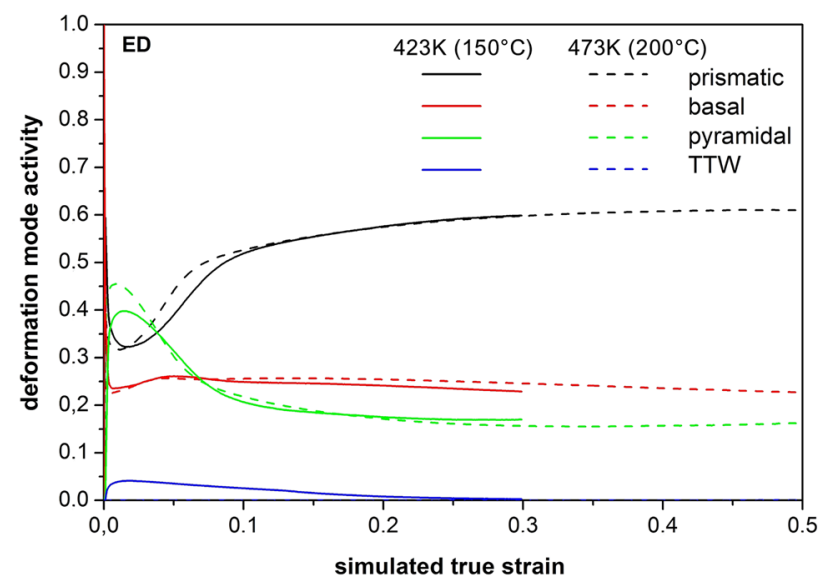

(b)

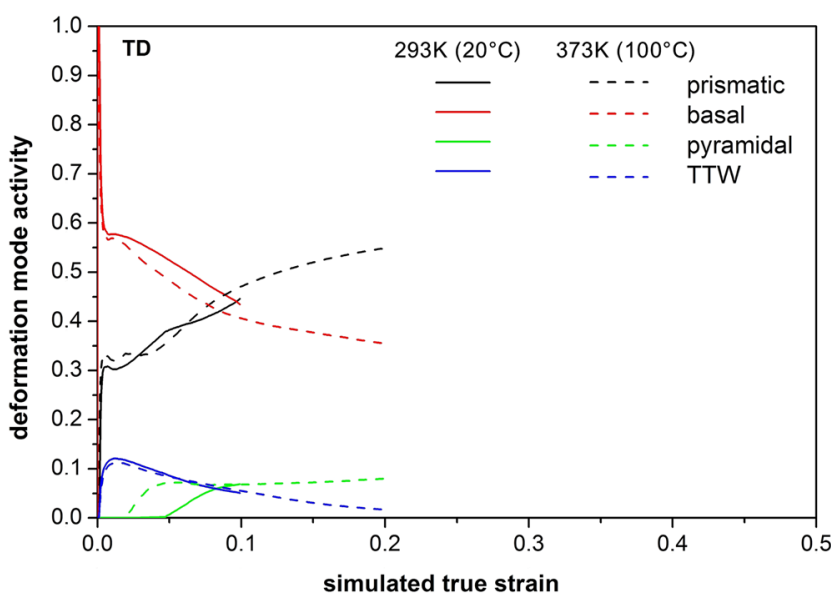

(c)

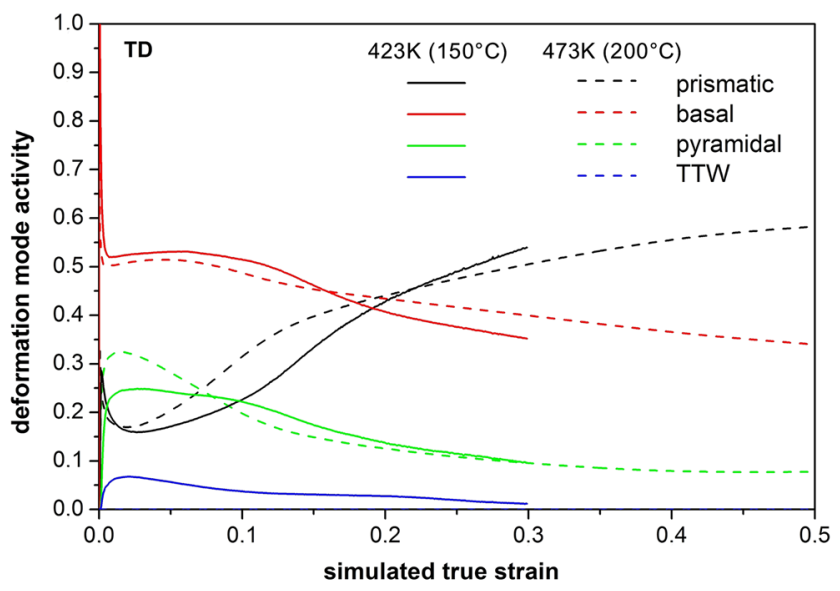

(d)

Fig. 9-Relative activities of the active deformation modes predicted by the EPSC model for $293 \mathrm{~K}$ and $373 \mathrm{~K}\left(20{ }^{\circ} \mathrm{C}\right.$ and $\left.100{ }^{\circ} \mathrm{C}\right)$ in $(a)$ and $(b)$ $\mathrm{ED} ; 423 \mathrm{~K}$ and $473 \mathrm{~K}\left(150{ }^{\circ} \mathrm{C}\right.$ and $\left.200^{\circ} \mathrm{C}\right)$ in $(c)$ and $(d) \mathrm{TD}$ (Color figure online).

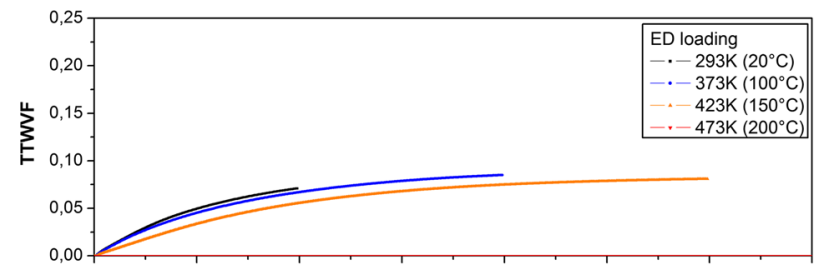

(a)

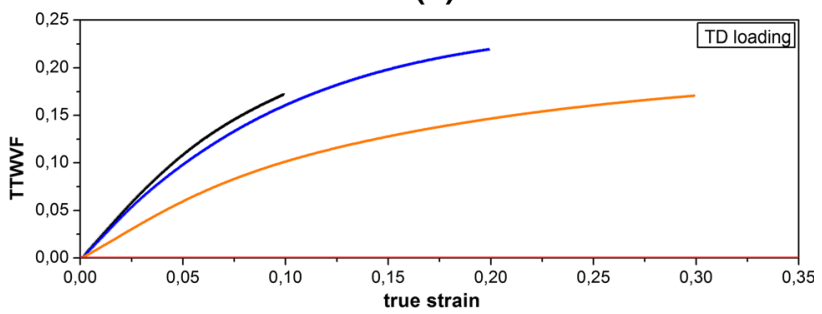

(b)

Fig. 10-TTWVF as a function of strain for $293 \mathrm{~K}, 373 \mathrm{~K}, 423 \mathrm{~K}$, and $473 \mathrm{~K}\left(20^{\circ} \mathrm{C}, 100{ }^{\circ} \mathrm{C}, 150{ }^{\circ} \mathrm{C}\right.$, and $\left.200{ }^{\circ} \mathrm{C}\right)$ in dependence of loading direction: (a) $\mathrm{ED}$ and (b) TD (Color figure online). different slip systems, particularly in the initial stages of straining when the texture effect would be strong.

From Figure 9, we see that twinning plays a minor role. Its participation decreases as temperature increases. Figure 10 shows more explicitly the change in twinning with temperature. The small amount of twinning predicted here explains why the signatures of twinning were not observed in the macroscopic stressstrain response and also in the texture evolution. Extension twinning usually leads to an increase in hardening rate with strain and an abrupt $86.3 \mathrm{deg}$ reorientation of the basal poles, and both features are not pronounced in the cases studied here.

Within the model, the activation barriers for the formation and expansion of twins were presumed temperature insensitive, so the temperature-dependent macroscopic change in the amount of twinning seen in Figure 9 is a direct consequence of thermally activated slip. As slip becomes relatively easier with increases in temperature, slip plays a larger role and twinning a smaller one. 
The initial yield stress is determined by the slip systems activated at strains covering the macroscopic yield point. In both the ED and TD tests, pyramidal slip participates at the higher temperatures [ $423 \mathrm{~K}$ and 473 $\mathrm{K}\left(150^{\circ} \mathrm{C}\right.$ and $\left.\left.200^{\circ} \mathrm{C}\right)\right]$ but not the lower ones based on the temperature dependence of its friction stress ( $c f$. Figure 8). The variation in the amounts of pyramidal slip with temperature is larger for the ED than the TD, explaining why the yield stress in the ED was slightly more sensitive to temperature than that in the TD.

The initial hardening rates, after yield, are governed by the accumulation of dislocations on the more dominant slip (or twinning) mode. According to Table II, the trapping rate for prismatic slip is found to be highest compared to that for the other slip modes. This explains why the ED tensile response, which involves more prismatic slip throughout tensile deformation, exhibited a higher strain-hardening rate after yield than the TD tensile response.

For most of the straining period of the tests, $\langle a\rangle$ slip dominates, whether prismatic or basal slip, at all temperatures and loading directions. Pyramidal $\langle c+a\rangle$ slip plays a smaller role in all cases. However, the relative amounts of pyramidal $\langle c+a\rangle$ slip increase as temperature increases. At $473 \mathrm{~K}\left(200{ }^{\circ} \mathrm{C}\right)$, the contribution is the highest. Promotion of $\langle a\rangle$ and $\langle c+a\rangle$ multislip leads to more homogeneous slip and, hence, deformation, so that it likely explains why the elongation to failure is the highest in the TD and ED at the highest temperature $473 \mathrm{~K}\left(200{ }^{\circ} \mathrm{C}\right)$ (Figures 3 and 4$)$.

The highly temperature-dependent pyramidal $\langle c+a\rangle$ participation is linked to its highly temperature-dependent activation barrier, predicted by the model in Figure 8. The initial CRSS for $\langle c+a\rangle$ slip is found to rapidly decrease with temperature, reaching those of prismatic and basal slip at $473 \mathrm{~K}\left(200{ }^{\circ} \mathrm{C}\right)$. The near equalization of slip activation would result in more homogeneous deformation and higher elongations to failure as temperature increases (Figure 4). It also reduces the likelihood for deformation twinning, since pyramidal $\langle c+a\rangle$ slip directly competes with twinning for accommodating $\langle c\rangle$-axis extension.

Because the CRSS values become closer as temperature increases, the relative amounts of the three slip modes become similar; this explains the reduction in the ED-TD PA with increases in temperature. Generally, the more equivalence among the CRSS values for slip, more activated slip, the more homogeneous plastic deformation is and the lower the stress concentrations that develop. Prior studies suggest that stress concentrations, which lead to material failure, are caused by a lack of plastic relaxation mechanisms. ${ }^{[15,18]}$ As a consequence, it is assumed that more active deformation modes relieve stress concentrations. The simulated changes in the CRSS values, therefore, effectively help to postpone instabilities (e.g., stress concentrations) and lead to higher elongations to fracture.

These relative activities provide clues as to why the elongation to failure in the TD is larger than that in the ED. As shown in Figure 4, the elongations to failure improve more in the TD than in the ED as temperature increases. One widespread conventional thought is that more pyramidal slip and less twinning improve ductility. While the results here do not contradict this notion, it is interesting to note that the higher ductility for the TD arises, although TD deformation involves less pyramidal slip and more twinning than ED deformation for the same temperature. We observe, however, that TD deformation generally involves more of the easy basal slip than does ED deformation throughout its deformation history, which may be one reason for the better ductility in this test direction.

As seen in Figures 5 and 6, the textures in ED and TD tension at failure are significantly different, suggesting, as we mentioned, different relative slip activities. Calculations of the average relative activities in the polycrystal in Figure 9 reveal that in the initial straining periods, basal slip dominated in the TD and prismatic slip in the ED. For the ED, the predominance of prismatic slip was maintained, which agrees with the IMGA results. For the TD, however, the prevalence of basal slip was not maintained. Eventually, at a given strain level, the relative activity of prismatic slip equals that of basal. With further straining, it surpasses basal slip and eventually predominates the remainder of the deformation test. Hereby, it should be noted that the TD split, which is parallel to the loading direction for TD loading, initially supports the basal slip regarding the Schmid factors; however, the motion of the TD split toward the ND will continuously decrease the Schmid factor of basal slip.

In connection with texture, we find that the two $\langle a\rangle$ slip modes have distinct effects on texture evolution ( $c f$. Figure 9). In ED tension, the relative amounts of slip remain stable; hence, the texture stabilizes with the peak components remaining close to those found in the initial texture. Slip activities also do not change significantly with temperature; consequently, the texture is not greatly affected by temperature. In TD tension, however, the predominant $\langle a\rangle$ slip mode changed during deformation from basal to prismatic, and the strain at which this transition took place depends on temperature. Thus, the temperature-sensitive texture development in the TD is a consequence of the effect temperature had on this transition.

As a final point on texture, it is interesting to note that even by the failure strain, the ED and TD textures for the same temperature are not the same, signifying that the initial texture had a strong effect on texture development during the entire deformation process. Further, it is also worth noting that the difference in the ED- and TD-tension textures at failure only increases with temperature. This may be surprising, since, as we have shown, for the highest temperature, the CRSS values among the three slip systems are the closest and the deformation strains are the largest - two factors that are usually thought to help erase the effects of initial texture.

\section{CONCLUSIONS}

In this study, we used a combination of mechanical testing, texture analysis, and crystal plasticity modeling to understand the effects of elevated temperature on the 
plastic deformation response of an extruded Mg-4 wt pet Li alloy sheet. To connect the stress-strain response and texture evolution with the underlying active deformation mechanisms, we employ the EPSC model with a thermally activated dislocation density-based hardening law for activating slip. The initial texture is strong with two basal peaks tilted along the TD. Yield and flow stress decrease and elongations to failure increase as the temperature is raised from room temperature, to $373 \mathrm{~K}, 423 \mathrm{~K}$, and 473 $\mathrm{K}\left(100{ }^{\circ} \mathrm{C}, 150{ }^{\circ} \mathrm{C}\right.$, and $\left.200{ }^{\circ} \mathrm{C}\right)$. The results show that while the in-plane PA decreases with temperature, the anisotropy in failure strain and texture development concomitantly increase. The model achieves excellent agreement for all tests with a single set of intrinsic material parameters. The analysis indicates that the activation barriers for all slip families decrease with temperature, and for the $293 \mathrm{~K}$ to $473 \mathrm{~K}\left(20^{\circ} \mathrm{C}\right.$ to $\left.200{ }^{\circ} \mathrm{C}\right)$ range, basal slip is the easiest, prismatic slip harder, and pyramidal $\langle c+a\rangle$ the hardest. The model shows that at all temperatures, the deformation behavior is driven primarily by $\langle a\rangle$ slip and that $\langle c+a\rangle$ slip and twinning play a minor role. The results also suggest that the in-plane PA decreases and failure strains increase with temperature as a result of a significant reduction in the activation stress for pyramidal $\langle c+a\rangle$ slip, which effectively promotes strain accommodation from multiple types of slip. They imply that in-plane texture development differs because prismatic slip dominates the deformation in one test, while basal slip dominates in the other. These findings reveal insight into the effects of temperature on the thresholds needed to activate crystallographic slip and twinning and help in understanding the temperature-sensitive behavior of $\mathrm{Mg}-4$ wt pet Li under mechanical deformation.

\section{ACKNOWLEDGMENTS}

Two of the authors (MR and WR) are grateful for the financial support of the DFG under Contract No. 688/69-1. IJB gratefully acknowledges the STEM Women Visiting Scholars Program at UNH ADVANCE funded by NSF Grant No. 1209189. MK acknowledges the support of the U.S. National Science Foundation under Grant No. CMMI-1541918.

\section{REFERENCES}

1. B.L. Mordike and T. Ebert: Mater. Sci. Eng. A, 2001, vol. 302, pp. 37-45.

2. Partnership, USAM, Magnesium Vision 2020: A North American Automotive Strategic Vision for Magnesium, 2006.

3. M.H. Yoo: Mater. Trans. A, 1981, vol. 12, pp. 409-18.

4. C.S. Roberts: Magnesium and Its Alloys, Wiley, New York, 1960.

5. E.W. Kelly and W.F. Hosford: Trans. TMS-AIME, 1968, vol. 242, pp. 5-13.

6. X.Y. Lou, M. Li, R.K. Boger, S.R. Agnew, and R.H. Wagoner: Int. J. Plast., 2007, vol. 23, pp. 44-86.

7. T. Obara, H. Yoshinga, and S. Morozumi: Acta Metall., 1973, vol. 21, pp. 845-53.

8. S.R. Agnew and O. Duygulu: in Mechanisms Technology, Alan A. Lou, ed., TMS, Warrendale, PA, 2004, pp. 61-66.
9. Z. Keshavarz and M.R. Barnett: Scripta Mater., 2006, vol. 55, pp. 915-18.

10. O. Muránsky, D.G. Carr, M.R. Barnett, E.C. Oliver, and P. Sittner: Mater. Sci. Eng. A, 2008, vol. 496, pp. 14-24.

11. J.F. Stohr and J.P. Poirier: Magn. Phil. Mag., 1972, vol. 25, pp. 1313-29.

12. H. Yoshinaga, T. Obara, and S. Morozumi: Mater. Sci. Eng., 1973, vol. 12, pp. 255-64.

13. S.R. Agnew, M.H. Yoo, and C.N. Tomé: Acta Mater., 2001, vol. 49 , pp. $4277-89$.

14. T. Al-Samman and G. Gottstein: Mater. Sci. Eng. A, 2009, vol. 488, pp. 406-14.

15. M. Lentz, M. Risse, N. Schaefer, W. Reimers, and I.J. Beyerlein: Nat. Commun., 2016, vol. 7, article number 11068.

16. T. Al-Samman: Acta Mater., 2009, vol. 57, pp. 2229-42.

17. M. Lentz, M. Klaus, I.J. Beyerlein, M. Zecevic, W. Reimers, and M. Knezevic: Acta Mater., 2015, vol. 86, pp. 254-68.

18. S.R. Agnew, J.A. Horton, and M.H. Yoo: Metall. Mater. Trans. A, 2002, vol. 33A, pp. 851-58.

19. N. Stanford, R.K.W. Marceau, and M.R. Barnett: Acta Mater., 2015 , vol. 82 , pp. $447-56$.

20. M.R. Barnett, Z. Keshavarz, A.G. Beer, and X. Ma: Acta Mater., 2008, vol. 56, pp. 5-15.

21. M. Lentz, R.S. Coelho, B. Camin, C. Fahrenson, N. Schaefer, S. Selve, T. Link, I.J. Beyerlein, and E. Reimers: Mater. Sci. Eng. A, 2014, vol. 610, pp. 54-64.

22. R. Hielscher and H. Schaeben: J. Appl. Crystallogr., 2008, vol. 41, pp. 1024-37.

23. S. Gall, R.S. Coelho, S. Müller, and W. Reimers: Mater. Sci. Eng. $A, 2013$, vol. 579 , pp. $180-87$.

24. X. Li, T. Al-Samman, and G. Gottstein: Mater. Lett., 2011, vol. 65 , pp. $1907-10$.

25. X. Huang, K. Suzuki, Y. Chino, and M. Mabuchi: J. Alloys Compd., 2015, vol. 632, pp. 94-102.

26. P.A. Turner and C.N. Tomé: Acta Metall. Mater., 1994, vol. 42, pp. 4143-53.

27. J.D. Eshelby: Proc R. Soc. Lond., 1957, vol. A241, pp. 376-96.

28. A.R. Wazzan and L.B. Robinson: Phys. Rev., 1967, vol. 155, pp. 586-94.

29. M. Zecevic and M. Knezevic: Int. J. Plast., 2015, vol. 72, pp. $200-17$.

30. M. Zecevic, M. Knezevic, I.J. Beyerlein, and C.N. Tomé: Mater. Sci. Eng. A, 2015, vol. 638, pp. 262-74.

31. M. Knezevic, M. Zecevic, I.J. Beyerlein, J.F. Bingert, and R.J. McCabe: Acta Mater., 2015, vol. 88, pp. 55-73.

32. I.J. Beyerlein and C.N. Tomé: Int. J. Plast., 2008, vol. 24, pp. 867-95.

33. U. Essmann and H. Mughrabi: Phil. Mag., 1979, vol. A40, pp. $731-56$.

34. U.F. Kocks and H. Mecking: Progr. Mater. Sci., 2003, vol. 48, pp. 171-273.

35. H. Mecking and U.F. Kocks: Acta Metall. Mater., 1981, vol. 29, pp. $1865-75$.

36. B. Clausen, C.N. Tomé, D.W. Brown, and S.R. Agnew: Acta Mater., 2008, vol. 56, pp. 2456-68.

37. M. Yamasaki, K. Hagihara, S.I. Inoue, J.P. Hadorn, and Y. Kawamura: Acta Mater., 2013, vol. 61, pp. 2065-76.

38. R. Maddin and N.K. Chen: Progr. Met. Phys., 1954, vol. 5, pp. 53-59.

39. E.J. Rapperport and C.S. Hartley: Trans. TMS-AIME, 1960, vol. 218 , pp. $869-77$.

40. K.Y. Xie, Z. Alam, A. Caffee, and K.J. Hemker: Scripta Mater., 2016, vol. 112, pp. 75-78.

41. Q. Yu, L. Qi, R.A. Mishra, J. Li, and A.M. Minor: Proc. National Academy of Sciences of the United States of America, 2013, 110, pp. $13289-13893$.

42. S.E. Ion, F.J. Humphreys, and S.H. White: Acta Metall., 1982, vol. 30 , pp. 1909-19.

43. A. Couret and D. Caillard: Acta Metall., 1985, vol. 33, pp. $1447-54$.

44. A. Couret and D. Caillard: Acta Metall., 1985, vol. 33, pp. $1455-62$.

45. M.H. Yoo, S.R. Agnew, J.R. Morris, and K.M. Ho: Mater. Sci. Eng. A, 2001, vols. 319-321, pp. 87-92. 